\title{
VIKTOR VIKTOROVICH IVANTER
}

DOI: $10.1134 / \mathrm{S} 1075700719060157$

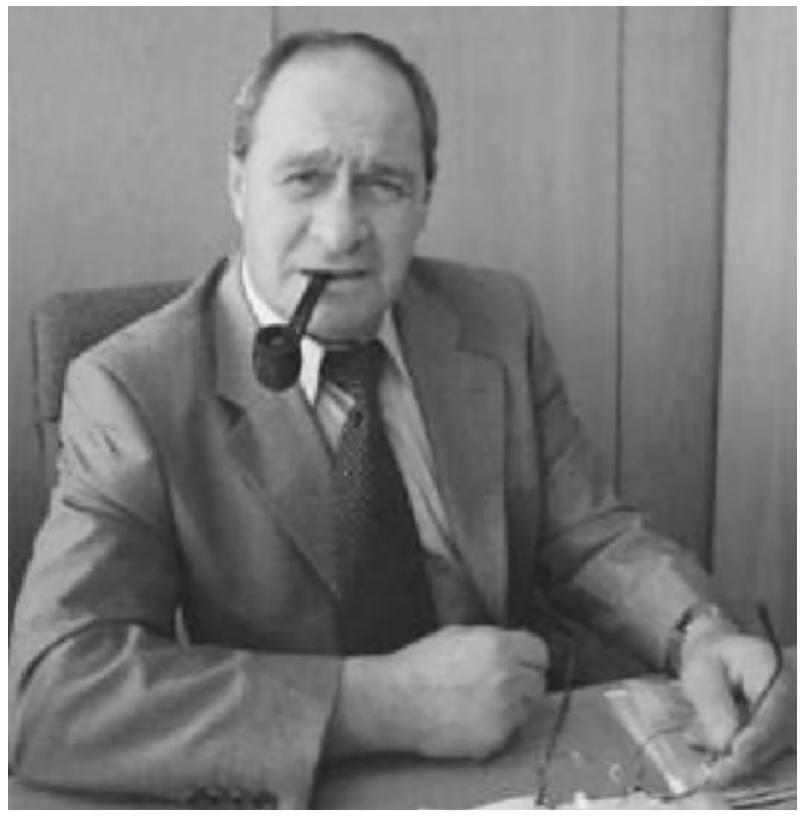

On September 15, 2019, Viktor Viktorovich Ivanter, academician of the Russian Academy of Sciences, editor-in-chief of our journal for more than 20 years, director (1997-2017) and scientific leader of the Institute of Economic Forecasting of the Russian Academy of Sciences (2017-2019) died suddenly. The scientific community and the general public knew academician V.V. Ivanter as an outstanding researcher and the leading authority in the field of macroeconomic analysis and forecasting, the founder of the domestic school of macro-financial forecasting, and one of the best specialists in the country on monetary and financial policies and the development of the banking system.

We, colleagues and students of Viktor Viktorovich, will remember him as a terrific person of extraordinary wisdom, deep knowledge, and an outstanding sense of humor. He always could take a fresh look at any scien- tific problem and offer completely novel and innovative approaches to solving it. This allowed him to start and lead regularly interesting research projects devoted to the analysis and forecasting of the socioeconomic development of Russia.

He could explain the most complex issues of economic science and macroeconomic policy very simply and intelligibly, in a language understood by everyone. At the same time, he left us a huge number of "economic" jokes and well-aimed expressions, which we will repeat for a long time. For many years, not only Russian and foreign colleagues have been carefully listening to Viktor Viktorovich's deep and non-trivial ideas, but also government leaders (although, as he often philosophically observed, "they listen but rarely hear"). Nevertheless, some ideas of Viktor Viktorovich regarding industrial and monetary policy, project financing, infrastructure development, etc. were embraced by individuals making economic decisions, and to a certain degree those ideas began to be used in Russia.

We always knew that Viktor Viktorovich, despite his emotionality, which was especially pronounced when discussing issues of principle, was a very kind person who maintained the most friendly atmosphere in the team and heartwarmingly looked after his teachers and senior colleagues. Viktor Viktorovich paid great attention to young employees, not only trying to involve them into interesting research projects but also to provide them with decent wages.

Viktor Viktorovich left behind an extremely significant scientific heritage in the form of numerous publications, the strong highly professional Institute, and the authoritative scientific school in the field of macroeconomic and macro-financial forecasting.

His memory will forever remain in our grateful hearts.

Publishers and authors of the journal 